OPEN ACCESS

Edited by:

Mariano Torcal,

Pompeu Fabra University, Spain

Reviewed by:

Jill Sheppard,

Australian National University,

Australia

Clara Volintiru,

Bucharest Academy of Economic

Studies, Romania

*Correspondence: Mikkel Stein Knudsen Mikkel.Knudsen@utu.fi

Specialty section:

This article was submitted to

Political Participation,

a section of the journal

Frontiers in Political Science

Received: 08 October 2021 Accepted: 10 November 2021

Published: 10 December 2021

Citation:

Knudsen MS and Christensen HS (2021) Future Orientation and Political Participation: The Moderating Role of Political Trust.

Front. Polit. Sci. 3:791467. doi: 10.3389/fpos.2021.791467

\section{Future Orientation and Political Participation: The Moderating Role of Political Trust}

\author{
Mikkel Stein Knudsen ${ }^{1,2 *}$ and Henrik Serup Christensen ${ }^{3}$ \\ ${ }^{1}$ Faculty of Social Sciences, Business and Economics, Åbo Akademi University, Åbo, Finland, ${ }^{2}$ Finland Futures Research Centre, \\ University of Turku, Turku, Finland, ${ }^{3}$ Department of Political Science, Åbo Akademi University, Åbo, Finland
}

Previous studies show consistent differences in how people evaluate future consequences and implications of this for a variety of phenomena. The implications for the individual propensity for taking part in different forms of political participation have received limited scholarly attention, however. This is unfortunate since it affects how people voice their concerns over future problems and thereby also whether and how decision-makers become aware of these concerns. We here examine this in a cross-sectional study conducted in Finland ( $N=1,673)$. We apply the Considerations of Future Consequences (CFC) framework as a measure of individuals' future orientation and distinguish between considerations of future consequences (CFC-future) and considerations of immediate consequences (CFC-Immediate). We study the direct associations with institutionalized and non-institutionalized political participation and the moderating role of political trust in shaping these associations. Our results show CFCfuture has a positive association with both institutionalized and non-institutionalized political participation, while CFC-immediate has a negative association with participation. Political trust moderates the association with non-institutionalized political participation since the association is stronger for citizens with low political trust. This may suggest that citizens use particular participatory avenues to communicate their worries over future problems, and to which decision-makers must be attentive.

Keywords: future orientation, political participation, considerations of future consequences, political trust, time perspective

\section{INTRODUCTION}

Aesop's famous fable of The Ant and the Grasshopper crystallizes the impact of time perspectives: The grasshopper spends the summer singing, while the ant stores up food for winter. By December, the hungry grasshopper begs the ant for food, but the ant merely tells it to dance the winter away. Without passing moral judgment on either, we note that during the summer the grasshopper is more concerned with its immediate environment, while the ant is more concerned about the future. The dilemma between immediate consumption and saving for later remains at the heart of human existence: We are torn between an impulse to act like the grasshopper and an awareness that the ant often gets ahead in the long run (McClure et al., 2004; Schafer, 2021).

The ability to evaluate future consequences is thus a fundamental aspect of human decisionmaking (Kable, 2014), but individuals evaluate future consequences in heterogeneous ways. Simplifying, on the continuum from the grasshopper to the ant, some are closer to the 
grasshopper, while others are closer to the ant. Temporal aspects of human psychology continue to attract interest in modern times. As elaborated below, this includes conceptual frameworks such as time perspective, temporal orientation, delayed gratification, and delay discounting. This article concerns the specific temporal frame of future orientation and examines this through the framework of Consideration of Future Consequences (CFC). Despite wide use elsewhere, this framework has received little previous attention in studies of political participation. However, the association between future orientation and political participation is important to study since it has repercussions for what types of future concerns mobilize citizens, and therefore conceivably also for what concerns are brought to the attention of formal political decision-makers.

Although the topic has received surprisingly little attention until recent years, temporal orientations have proven implications for the political sphere. Temporal orientation differs in political campaign communication (Müller, 2021) and political speech (Robinson et al., 2015), and time perception differences are seen to influence support for futureoriented policies (Pérez and Tavits, 2017). General temporal orientation also shows up in political thinking-people who are future-oriented in their daily lives also tend to be so for political issues (Rapeli et al., 2021). There are also strong previous indications of links between temporal orientation and political participation (see Fowler and Kam, 2006; Wang, 2018, 2019; Hill, 2020; Schafer, 2021), although earlier studies are more or less limited to certain aspects (primarily voting), a certain setting (United States), and a methodological preference for hypothetical choice batteries (delay discounting) rather than self-reporting scales such as CFC.

The CFC-scale is one of the most widely applied conceptualizations of all time orientation measurements (Murphy and Murphy, 2018; Mohammed and Marhefka, 2020). It is an individual difference originally developed as a one-factor scale defined as "the extent to which individuals consider the potential distant outcomes of their current behavior and the extent to which they are influenced by these potential outcomes" (Strathman et al., 1994). Individuals with high corresponding CFC-values are likely to consider the future implications of their current behavior more, while individuals with lower CFC-values are, relatively, more focused on immediate effects of current behavior. We would expect, in other words, the ant to score high on the CFC-scale, while the grasshopper would have a low CFC-value. The CFC-scale has later been adapted to a 14-item bidirectional scale, which differentiates between Consideration of Immediate Consequences (CFC-Immediate) and Consideration of Future Consequences (CFC-Future) (Joireman et al., 2012). Over the latest decade, the CFC-scale has been applied for numerous studies, which show correlations with e.g. individuals' beliefs and attitudes towards green policies, and health behavior (Dietz et al., 2007; Khachatryan et al., 2013; Joireman and Liu, 2014; Murphy and Dockray, 2018). Recently, higher levels of CFC-Future have also been found to correlate with a higher stated propensity for taking a COVID-19 vaccine (Ma and Ma, 2021). This article uses this most recent CFC-14 scale for examining links between future orientation and political participation and the moderating role of political trust.

The key motivation for this article is thus to deepen our understanding of the associations between the psychological concept of considerations of future consequences and various forms of political participation. We examine the links between the CFC-Future and CFC-Immediate scales and institutionalized and non-institutionalized political participation in a large-scale survey of citizens in Finland. This is to the best of our knowledge the first article to use the CFC-scale in connection with political participation between elections, as well as the first large-scale temporal orientation-political participation survey study outside the United States. In addition to this, we examine the moderating effect of political trust since this is likely to affect the extent to which future concerns lead to political action.

Our results show that higher values of CFC-Future are connected to participation in both institutionalized and non institutionalized participation, whereas CFC-Immediate tends to depress the propensity for participation, especially in noninstitutionalized activities. Furthermore, our results show that the relationship between CFC-Future and non-institutionalized participation is moderated by political trust, which entails that it is only for people with low levels of political trust that CFC-future increases the likelihood of participation. This thereby suggests that there is no reason to believe that those participating in noninstitutionalized political actions are less invested in the future than those participating in more institutionalized forms are.

\section{BACKGROUND}

We here use Consideration of Future Consequences (Joireman et al., 2012) as a measure of future orientation. CFC is the weighing of immediate and future consequences against each other (Strathman et al., 1994).

CFC is part of a larger set of concepts related to temporal orientation and time perspective. Time perspective is the temporal and multidimensional individual difference capturing the degree to which individuals subjectively focus on past, present, and/or future timeframes (Mohammed and Marhefka, 2020). The concept differs from related constructs such as temporal depth (the temporal distance into the past and the future) and temporal horizon (temporal distance into the horizon). Temporal orientation is derived from the higher hierarchical concept of time perspective and can specifically be conceptualized as the degree to which one attends to, is motivated, and engages in action towards the past, present, or future (Biondolillo and Epstein, 2021). Future time perspective (e.g. Kooij et al., 2018) and future orientation are conceptual subsets concerned with the specific temporal frame of the future. This is the most commonly researched temporal frame, with CFC one of the most widely applied operationalizations (Murphy and Murphy, 2018; Mohammed and Marhefka, 2020). Recent psychological research has also conceptualized CFC and future time perspective as one of five dimensions for a broader scale examining individuals' future consciousness (Ahvenharju et al., 
2018, 2021). The CFC-scale has been used in a Finnish context previously, (Vainio, Ovaska et al., 2019), but not with a focus on political behavior.

The CFC can be conceptualized either as a unidimensional or bidimensional construct. The two-factor, bidimensional construct is measured through a 14-item CFC scale (Joireman et al., 2012), with subscales for considerations of immediate consequences (CFC-Immediate) and considerations of future consequences (CFC-Future). The empirically validated bidimensional construct highlights that concern with future and concern with immediate consequences are not necessarily polar opposites (Joireman et al., 2012). The two dimensions, therefore, measure subtly different things. When it comes to the likelihood of exercise, for example, results might be driven not by concerns about long-term consequences (e.g. long-term health benefits), but rather by a concern with immediate consequences (e.g. inconvenience) (Joireman et al., 2012). Similarly, related to our study here, we may infer that a decision to not vote in an election may be a sign of lower consideration of future consequences (cf. Fowler and Kam, 2006) or a higher consideration of immediate consequences making the individual less likely to follow through on an intention to vote (cf. Hill, 2020).

The CFC-scale has been found to indicate policy beliefs regarding energy and the environment [see e.g. (Khachatryan et al., 2013; Blumer et al., 2018; Vainio, Varho, et al., 2019)], but the scale has, to the best of our knowledge, not been used in prior examinations of political participation. Other studies have, however, studied the link between connected concepts and forms of political participation, although often with a singular focus on voting.

This follows a turn in recent decades in which political scientists have turned towards politics in time, paying attention to how temporal elements such as timing, duration, tempo, sequencing, etc. influence patterns of political activity (Grzymala-Busse, 2011; Pierson, 2011).

While much of this research concerns various temporal aspects of the policymaking process, a few studies explore the role of temporal aspects associated with personality traits and the formation of preferences at the level of individuals (Jacobs and Matthews, 2012). This research challenges the oft-assumed notion that voters are fundamentally myopic and that the shortsightedness of both voters and politicians is to blame for many of democratic society's woes. Recent research suggests that voters may not be quite as short-sighted as previously assumed (Christensen and Rapeli, 2021), while other research suggests that incumbent elected politicians have longer time horizons than their respective electorates (Sheffer et al., 2018). While elected politicians do discount the future steeply, the average politician tends to discount it less steeply than the average citizen does.

Some previous studies assess associations between political participation and delay discounting. Delay discounting (the term often used in economics) and delay of gratification (often used in psychology) are closely linked to CFC and suggest the degree to which one devalues future outcomes as the delay to achieve those outcomes increases (Bickel and Marsch, 2001; Jacobs and Matthews, 2012), as the well as the capability of self-control to wait for the later, greater reward (Mischel et al., 1989; Falk et al., 2020). Earlier delay discounting/political participation studies generally focus exclusively on voting. Electoral voting involves a time perspective. When casting their ballot for candidates and parties, citizens consider retrospective (past performances) and prospective (promises for the upcoming legislative cycle) factors (Müller, 2021). The decision of whether to vote or not is also influenced by the temporal orientation of citizens. The process of voting requires an immediate effort, while the potential benefits from the election results are not borne out before after Election Day (foregoing for a second the potential positive social and selfimage effects gained from voting). The future-oriented strategic voter might even rationally choose a particular candidate without an expectation of reaping benefits before e.g. decades later (Downs, 1957).

This has led to a general political science theory that since rewards of voting are reaped later than costs, the act of voting correlates with delay discounting preferences. In their seminal study, Fowler and Kam (2006) coined this as "Patience as a Political Virtue". Their results demonstrated that college students discounting the future less steeply were more likely to have voted at a recent election. In other words, patient citizens, i.e. citizens with a higher willingness to wait for future rewards, have a higher propensity of voting. The study thereby proved empirical evidence for the theoretical notion that delay discounting preferences, or future orientation, constitutes an explanatory variable with political participation (voting) as the dependent variable. Similar results have later been found in broader studies after the inclusion of discounting choice batteries in national surveys (Wang, 2018; Schafer, 2021). Using similar material, Seth Hill (2020) extends the analytical findings to show that less patient voters are less likely to follow through on an intention to vote. In other words, immediate obstacles - such as bad weather - are more likely to keep someone otherwise interested from voting, if the person discounts future rewards more steeply.

A correlation between delay discounting and political participation have also been shown for other forms of participation than voting. For example, Schafer (2021) finds a similar relationship for campaign donations in the US. Wang (2019) links patience and participation in various stages of the 2004 Orange Revolution in Ukraine. Individuals with a higher level of patience are more likely to join a (pro-democracy) protest earlier, while there are still major uncertainties related to both the temporal length and the likelihood of success. As demonstrations continue - and the future outcome becomes closer and the risk of punishment decreases - latecomers with moderate levels of patience also join the protests. Israeli researchers surveyed 192 MBA students 2 months after the end of the 2011 Israeli social justice protests and found that respondents with lower subjective discount rates - i.e. less present-oriented - had been more likely to take part in the protests (Shavit et al., 2014).

In a general and formalized model, Meirowitz and Tucker (2013) use equations to "demonstrate how those with a less myopic view of current events may be more willing to protest, which suggests an interesting avenue for future research". They note further that it is "hardly earth-shattering" to observe that 
individuals with longer time horizons are more likely to undertake actions that are costly today but could yield potential benefits at a later stage. However, with the use of the model, it can also be stipulated that information on the patience levels/discount rates/future orientations of individuals, "we should be able to get a good predictor of who protests". This suggestion is reinforced by the work of Ting (2017), who with the use of qualitative interviews as source material highlights future orientation as an important driver for participation in youth activism in Hong Kong.

On a surface level, this framing of patience as an indicator of political protest runs counter with the recent framing of (collective) impatience as a motivation for radical political change (Basta, 2020). Through exhaustion framing, political mobilizers aim to shorten the time horizon within which the status quo policies must be changed. The political rupture interplay between the comparatively short collective time horizons and the comparatively long temporal horizons of the individuals involved in the process is a promising topic for future research.

While these studies provide important insights, the empirical findings are sparse, and they do not make it possible to distinguish how different considerations of future consequences shape political behavior. This is important since it has repercussions for what sort of political demands are transmitted to decision-makers through various modes of participation, and it ultimately may even influence the consequences of political participation for the long-term sustainability of democracy.

Political participation is often considered the lifeblood of democracy as a vibrant democracy requires that the citizenry is willing and able to interact with elected decision-makers also outside of the electoral arena (Verba et al., 1995; Norris, 2002). A participatory notion of democracy holds that greater public involvement provides better political decision-making, benefits political legitimacy of policy outcomes, and promotes essential civic attributes among participants (Pateman, 1970).

Political participation is a multifaceted concept that has been defined in many different ways (see e.g. Van Deth, 2014). Following Brady (1999), we define political participation as action by ordinary citizens towards influencing some political outcomes. This broad conceptualization highlights that the repertoire of political activists has expanded noticeably in recent decades (Norris, 2002; Van Deth, 2014). Accordingly, we in our empirical analyses focus on two modes of participation between elections frequently termed institutionalized and non-institutionalized participation (Marien et al., 2010; Bäck and Christensen, 2016). Although this simple distinction may fail to capture all relevant differences between political activities (Van Deth, 2014), it calls attention to a fundamental difference between political activities and their consequences over time, which is particularly relevant for the present purposes.

Institutionalized political actions include various activities that are directly related to the formal political system, such as campaign activities, contacting elected officials, and being active in a political party. These activities have traditionally formed an integral part of representative democracy and are considered the proper way for citizens to voice their preferences. However, several studies document that participation in these activities has diminished sharply since the 1960s in most countries (Kaase 1999; Norris 2002; Marien, Hooghe, and Quintelier 2010; Stolle and Hooghe 2011). This drop has been countered by an increase in non-institutionalized participation, which refers to activities outside of the formal political sphere where citizens in a bottom-up manner voice their political demands through ad-hoc and more spontaneous activities (Kaase, 1999; Stolle and Hooghe, 2011; Bäck and Christensen, 2016). Examples are Internet campaigns, ad hoc protests, political consumerism and lifestyle politics, etc. (Stolle and Hooghe, 2011). These non-institutionalized activities are often used to challenge the political elite, while the institutionalized activities serve to preserve the existing patterns of power (Bäck and Christensen, 2016). Previous empirical studies have found consistent patterns in who uses these two modes of participation (Marien et al., 2010; Stolle and Hooghe 2011; Bäck and Christensen 2016). It is generally found that older generations who feel that the representative system is working well are more likely to make use of the institutionalized forms of participation. Conversely, it is younger generations who feel that the formal political system excludes them from influencing political decisions who resort to non-institutionalized political participation.

For the present purposes, it is particularly valuable to observe that institutionalized participation requires long-term engagement where ideological goals may at best be achieved after several years, whereas non-institutionalized participation is frequently more episodic and involve sudden outbursts aimed to achieve specific issues, but not sustained involvement. Some assert that the proliferation of new non-institutionalized forms of participation may actually harm democracy since these activities are less likely to help activists achieve their intended goals (Van Deth, 2014). As noted by Stolle and Hooghe (2011: 139), there is a risk that the sporadic and short-lived nature of non-institutionalized activities prevent the transmission of political goals from participants to relevant decision-makers and make it difficult to sustain important political issues and empower citizens.

This central difference assumed within that line of thinking entails that the associations between CFC and political participation are likely to differ as well. For institutionalized political participation between elections, we may expect that higher values on CFC-Future are connected with higher levels of mobilization while CFC-Immediate is associated with lower levels of participation. Institutionalized activities entail a longterm commitment to furthering ideological goals through timeconsuming activities where there is a need for a focus on future pay-offs rather than immediate gains.

This is operationalized in our hypotheses $\mathrm{H} 1 \mathrm{a}$ and $\mathrm{H} 1 \mathrm{~b}$ below.

H1a: There is a positive association between CFC-Future and institutionalized political participation.

$\mathrm{H} 1 \mathrm{~b}$ : There is a negative association between CFC-Immediate and institutionalized political participation.

Our hypotheses are here in line with the previous studies discussed above (Fowler and Kam, 2006; Wang, 2018; Hill, 2020; Schafer, 2021), under the two key assumptions that patterns of institutionalized political participation between elections mirror patterns of voting behavior, and that CFC-scale responses share 
similar patterns as responses elicited through discounting choice batteries.

For non-institutionalized participation, the expectations are less clear-cut. Some consider non-institutionalized activities as pick-andchoose political participation where participation is easier for the individual and it requires fewer commitments, less long-term engagement, and perhaps less patience compared to institutionalized activities. Based on this, one might speculate that non-institutionalized political participation attracts those with a more immediate time horizon while those with a long-term focus eschew such activities. However, some consider non-institutionalized participation as a form of responsibility-taking, where citizens take matters into their own hands to accomplish (Dalton, 2008). Hence, it cannot be taken for granted that non-institutionalized participation entails a disdain for future consequences. For example, engagement in Fridays for Future protests was driven by intense long-term worries over climate change (Huttunen, 2021). According to this line of reasoning, we may expect that CFC-Future has a positive association with non-institutionalized participation as well.

While the expectations for non-institutionalized participation are less straightforward, we here proceed with a hypothesis based on the observation that these activities are more spontaneous and expressive, meaning they may be more appealing to individuals who consider immediate consequences:

$\mathrm{H} 2 \mathrm{a}$ : There is a negative association between CFC-Future and non-institutionalized political participation.

$\mathrm{H} 2 \mathrm{~b}$ : There is a positive association between CFC-Immediate and non-institutionalized political participation.

These hypotheses are not directly informed by previous studies of future orientation, where distinctions between institutionalized and non-institutionalized activities have not previously been examined. Here, however, we test an important potential distinction informed by the above political science-literature, namely the suggestion that those participating in bottom-up activities often assumed to be more ad hoc, more spontaneous and more short-lived are less concerned about future consequences and more concerned about immediate consequences than average citizens.

This brings us to the role of political trust in shaping the associations between CFC and political participation. The role of political trust in fostering political participation has been debated, and research suggests that political trust has a positive association with institutionalized participation, meaning more political trust promotes this type of participation, while it is negative for noninstitutionalized activities, meaning those with low trust are more likely to be active (Hooghe and Marien, 2013). However, we are here more interested in examining how the level of political trust affects the associations between our CFC measures and political participation. Political trust has been found to be an important moderator for other attitudinal and behavioral aspects (Abrams and Travaglino, 2018; Lim and Moon, 2020). Our examination of trust as a moderating factor is in line with the suggestion of (Joireman et al., 2012) that many CFC/health behavior studies have taken an "interactionist" perspective, in which moderating variables have different impacts on high and low CFC-scores. In this case, it may well be that the association between CFC and participation differs depending on political trust. When trust in political actors is low, it seems less likely that people worried over future consequences will use institutionalized participation to voice their concerns, since these actions target the same political institutions and actors they distrust. Hence, we may expect a negative moderation of the association. On the other hand, non-institutionalized activities that challenge the existing patterns of power may become a more appealing way to voice worries over future concerns. This line of reasoning mirrors Gamson (1968), who argue that a combination of low trust and high efficacy is what compels people to mobilize in protest. In a similar vein, the urgent belief that future problems need to be resolved now in combination will a low trust in the willingness of political actors to do so is a compelling mixture for activating people. However, since there are no prior studies of this relationship, our hypothesis $\mathrm{H} 3$ remain on the general level with the literatureinformed expectation that moderating effects exist:

H3: Political trust moderates the associations between CFC and political participation.

\section{RESEARCH DESIGN}

Figure 1 shows a graphical representation of the linkages under examination and how the hypotheses relate to each of the associations between the variables. The direct associations between CFC and political participation are examined in $\mathrm{Hla}$ $+\mathrm{b}$ and $\mathrm{H} 2 \mathrm{a}+\mathrm{b}$, while the moderating effects of political trust on these associations are examined under $\mathrm{H} 3$.

\section{Data}

The research data come from a survey administered to the internet panel Kansalaismielipide, which is administered by the Social Science Research Institute at Åbo Akademi University and forms part of the Finnish Research Infrastructure for Public Opinion (FIRIPO). At the time of the survey, the panel consisted of 2,285 Finnish citizens. Approximately sixty percent of the pool of respondents consists of respondents recruited using a random sample and mail invitations. The rest of the respondents have been recruited through advertising on various online and social media channels.

The survey was fielded 23 September-7 October 2020 using the online survey platform Qualtrics in both national languages Finnish and Swedish. A reminder was sent after 1 week to all respondents who had not yet completed the survey. A total of 1,673 responses were recorded, meaning the response rate was $73.2 \%$. Out of these 1,673 responses, 1,563 or 93 percent were complete responses where most survey items were filled out, meaning some respondents are excluded in the analyses due to missing data. ${ }^{1}$

\footnotetext{
${ }^{1}$ The survey respondents are not representative of the Finnish population. We tried to correct for non-response and sampling bias by calculating weights that adjusted for gender, region, age and education (iterative proportional fitting or raking). However, weighting the results did not alter the substantial results regression models, as may be expected since most of the socio-demographic variables were included as control variables (Gelman 2007). Since we do not generally aim to provide percentage estimates for the population, the results are unweighted unless noted otherwise.
} 


\section{Explanatory variable Dependent variable}

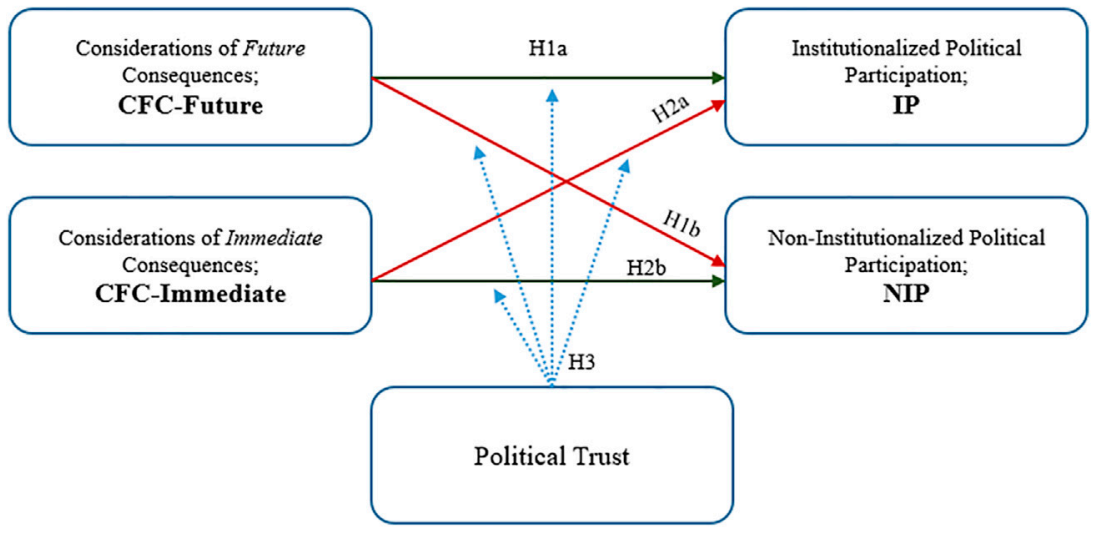

Moderating variable

FIGURE 1 | Graphical model of expected associations. Green arrow: Expected positive association. Red arrow: Expected negative association. Dashed arrow: Any association expected.

Finland presents an interesting case for our purposes. Finland is a thriving democracy with relatively high levels of political participation in and between elections (Borg et al., 2020), and the political climate has placed a strong emphasis on the importance of the future in political decision-making. The clearest manifestation is the establishment of the Committee for the Future in the Finnish parliament to generate dialogue with the government on major future problems and opportunities (Koskimaa and Raunio, 2020). There have also been several attempts of involving civil society and the Finnish general public in future-oriented political initiatives (Kettunen, 2015; Kurki, 2021). All of this entails that Finland provides a fertile environment for examining the links between future orientations and political behavior, although it might suggest limitations for the generalizability of the results.

The survey data was collected during the ongoing COVID 19pandemic, which could affect individuals' temporal considerations as well as their inclination for political participation. However, there are several reasons to believe that this does not invalidate our conclusions. During the time of the survey, i.e. the period between the summer of 2020 and the following winter, case numbers in Finland were low, and the society experienced only limited political interventions (for further information on the situation in Finland during the time of the survey, see e.g. Tiirinki et al., 2020). Furthermore, studies suggest that the pandemic has a limited effect on substantial effects, although estimates may be slightly weaker (Peyton et al., 2021). We therefore do not find reason to believe that the COVID-19 pandemic affects the results of the study.

\section{Measures}

The survey included a 14-item battery of CFC (see table 1) that replicates the one used by Joireman et al. (2012).
We examine the dimensionality of these with exploratory factor analysis (principal component factoring with promax rotation) where we extract all dimensions with an eigenvalue greater than 1 , as shown in Table 2 . $^{2}$

The results largely replicate the dimensionality reported by Joireman et al. (2012), which means that we label the first dimension CFC-Future and the second dimension CFCImmediate. Confirmatory Factor Analysis (CFA) also indicates that a two-factor solution provides a satisfactory fit $(\mathrm{CFI}=0.944$; $\mathrm{TLI}=0.933$; RMSEA $=0.057)$. Based on the results, we predict two standardized variables measuring each of these $(\mathrm{M}=0.00, \mathrm{SD}$ $=1.00$ ). Since histograms showed a few clear outliers (see Appendix), we excluded eight respondents with scores below three SD on the CFC-Future scale and 10 respondents with scores exceeding three SD on the CFC-Immediate scale.

To measure political participation, we rely on a battery of questions asking respondents whether they had performed various political activities performed between elections (2), would be willing to do so even if they had not (1), or had not and would not (0). As shown in Table 3, the activities include both traditional political activities such as being active in political parties, and more unconventional and elite-challenging activities such as demonstrations, boycotting, and political consumerism. ${ }^{3}$

We examine the dimensionality with a polychoric exploratory factor analysis to take into account that the observed variables are

\footnotetext{
${ }^{2}$ This Kaiser criterion has been known to cause too many factors to be extracted, so we double-checked the number of extracted factors with both parallel analysis and the scree plot. Both lead to the conclusion that two dimensions were adequate. ${ }^{3} \mathrm{We}$ excluded four activities with little variation or unclear loadings on the two dimensions extracted (Use violence to reach political goals, Civil disobedience by participating in illegal, non-violent activities, Wear/display campaign badge or sticker, Posted or shared political content online).
} 
TABLE 1 | Consideration of future consequences-14 scale.

\begin{tabular}{|c|c|}
\hline CFC\# & Phrasing \\
\hline 1 & I consider how things might be in the future, and try to influence those things with my day to day behavior \\
\hline 2 & Often I engage in particular behavior in order to achieve outcomes that may not result for many years \\
\hline 3 & I only act to satisfy immediate concerns, figuring the future will take care of itself \\
\hline 4 & My behavior is only influenced by the immediate (i.e., a matter of days or weeks) outcomes of my actions \\
\hline 5 & My convenience is a big factor in the decisions I make or the actions I take \\
\hline 6 & I am willing to sacrifice my immediate happiness or well-being in order to achieve future outcomes \\
\hline 7 & $\begin{array}{l}\text { I think it is more important to take warnings about negative outcomes seriously even if the negative outcome will not occur for } \\
\text { many years }\end{array}$ \\
\hline 8 & $\begin{array}{l}\text { I think it is more important to perform a behavior with important distant consequences than a behavior with less important } \\
\text { immediate consequences }\end{array}$ \\
\hline 9 & $\begin{array}{l}\text { I generally ignore warnings about possible future problems because I think the problems will be resolved before they reach } \\
\text { crisis level }\end{array}$ \\
\hline 10 & I think that sacrificing now is usually unnecessary since future outcomes can be dealt with at a later time \\
\hline 11 & I only act to satisfy immediate concerns, figuring that I will take care of future problems that may occur at a later date \\
\hline 12 & Since my day-to-day work has specific outcomes, it is more important to me than behavior that has distant outcomes \\
\hline 13 & When I make a decision, I think about how it might affect me in the future \\
\hline 14 & My behavior is generally influenced by future consequences \\
\hline
\end{tabular}

Source: Joireman et al. (2012)

Question: For each of the statements shown, please indicate how characteristic the statement is of you on a scale 1-7, where "1" means extremely uncharacteristic of you (not at all like you), while "7" means extremely characteristic of you (very much like you).

\begin{tabular}{lcc}
\hline TABLE 2 | Exploratory factor analysis of CFC items (PCF with promax rotation). \\
\hline Variable & Dim 1: CFC-future & Dim 2: CFC-immediate \\
\hline CFC13 & 0.80 & 0.24 \\
CFC14 & 0.73 & -0.14 \\
CFC1 & 0.72 & -0.13 \\
CFC2 & 0.70 & -0.03 \\
CFC6 & 0.58 & -0.10 \\
CFC7 & 0.55 & -0.23 \\
CFC8 & 0.54 & -0.17 \\
CFC3 & -0.03 & 0.77 \\
CFC11 & -0.12 & 0.70 \\
CFC9 & -0.14 & 0.62 \\
CFC5 & 0.23 & 0.62 \\
CFC10 & -0.19 & 0.60 \\
CFC4 & -0.14 & 0.59 \\
CFC12 & 0.16 & 0.59 \\
\hline Eigenvalue & 5.25 & 1.52 \\
\hline Kaiser & &
\end{tabular}

Kaiser-Meyer-Olkin Measure of Sampling Adequacy $(K M O)=0.919$; Bartlett test of sphericity $\left(\chi^{2}=6,822.99 ; d f=91\right), p<0.000$. Eigen value for third factor 0.923 .

ordinal scale with only three categories. We report the results in Table 3.

The results replicate previous studies in suggesting that political participation between elections is two-dimensional and that the sub-dimensions concern non-institutionalized and institutionalized participation (Marien et al., 2010; Stolle and Hooghe, 2011; Bäck and Christensen, 2016).

We operationalize institutionalized and non-institutionalized political participation using sum-variables where all variables with a loading $>0.6$ form part of a dimension, meaning we have an index measuring non-institutionalized participation (NIP; consumer boycott + political consumerism + sign citizens' initiative + sign petition + demonstration; $\mathrm{M}=74.58, \mathrm{SD}=19.26$, alpha $=0.73)$ and institutionalized participation (IP; letter to editor + contacting + party activities + voluntary associational activity; $\mathrm{M}=60.22, \mathrm{SD}=22.08$, alpha $=0.66$. The indexes were subsequently recoded to vary between 0 and 100, with higher scores indicating higher levels of participation.

The moderating variable in this study is political trust, which we measure with an index based on answers to the level of trust in parliament, political parties, politicians, and government, each rated on a $0-10$ scale. Exploratory factor analysis indicates that the index based on all four items is a one-dimensional construct (Eigenvalue 3.09), and we, therefore, use a single index scored $0-10(\mathrm{M}=5.19, \mathrm{SD}=2.08$, alpha $=0.89)$.

We include the following basic socio-demographic characteristics as control variables: age in years $(\mathrm{M}=54.99, \mathrm{SD}=15.94)$, gender (48.6\% female, $51.4 \%$ male, 24 respondents indicating "Other" excluded), Highest level of education (Basic (Primary + Lowersecondary) 3.4\%, Intermediate (Short vocational + College-level vocational + Upper secondary) 34.8\%, and Advanced (Polytechnic + University) 61.9\%; 20 respondents indicating "Other" excluded), Household income after taxes (seven-graded scale 0 (Less than $€ 1,000$ )-1 (More than $€ 6,000$ ), 152 respondents with missing values excluded, $\mathrm{M}=0.51, \mathrm{SD}=0.29)$ and marital status (Married or cohabiting 66.9\%, Single (including widowed and divorced) 33.2\%; 43 respondents indicating “Other" or "Don't know/ Don't want to say" excluded). These factors have been found to be important predictors for political participation in Finland and elsewhere (Marien et al., 2010; Stolle and Hooghe, 2011; Bäck and Christensen, 2016). We do not control for other political attitudes since these are likely to be affected by CFC and/or political participation and controlling for these may therefore bias the estimated effects ( $\mathrm{Li}, 2021)$.

Table 4 summarizes the main variables in the study.

\section{RESULTS}

Table 5 shows pairwise correlations between the central variables of the study. 
TABLE 3 | Exploratory factor analysis of political participation (Polychoric with promax)

Dim1:

Non-institutionalized participation

Join a consumer boycott

Try to influence political or social issues through my consumer choices

Sign a citizens' initiative

Sign a petition

Participate in peaceful demonstrations

Participate in the activities of a political party

Contact politicians or civil servants on an issue

Write a letter to the editor

Participate in the activities of some other voluntary/civic organization

Eigenvalue

$\begin{array}{lc}0.83 & -0.08 \\ 0.79 & -0.09 \\ 0.78 & 0.03 \\ 0.76 & 0.10 \\ 0.73 & 0.09 \\ -0.08 & 0.85 \\ 0.01 & 0.82 \\ -0.03 & 0.67 \\ 0.21 & 0.65 \\ 3.96 & 1.51\end{array}$

Kaiser-Meyer-Olkin Measure of Sampling Adequacy $(K M O)=0.788$; Bartlett test of sphericity $\left(\chi^{2}=2,223.27 ; d f=36\right), p<0.001$. Eigen value for third factor 0.94.

\begin{tabular}{|c|c|c|c|c|c|}
\hline Variable & Obs & Mean & Std. Dev & Min & Max \\
\hline CFC_Future & 1,523 & 0.00 & 1.00 & -4.17 & 2.41 \\
\hline CFC_Future (excluding outliers) & 1,515 & 0.02 & 0.97 & -2.96 & 2.41 \\
\hline CFC_Immediate & 1,523 & 0.00 & 1.00 & -2.22 & 4.79 \\
\hline CFC_Immediate (excluding outliers) & 1,513 & -0.03 & 0.96 & -2.22 & 2.97 \\
\hline Political trust & 1,566 & 5.19 & 2.08 & 0.00 & 9.50 \\
\hline Institutionalized participation (IP) & 1,255 & 60.22 & 22.08 & 0.00 & 100.00 \\
\hline Non-institutionalized participation (NIP) & 1,375 & 74.58 & 19.26 & 0.00 & 100.00 \\
\hline Age & 1,667 & 54.99 & 15.94 & 18.00 & 88.00 \\
\hline Gender & 1,649 & & & 1.00 & 2.00 \\
\hline Women & 801 & & & 1.00 & 1.00 \\
\hline Men & 848 & & & 2.00 & 2.00 \\
\hline Education & 1,628 & & & 1.00 & 3.00 \\
\hline Basic & 55 & & & 1.00 & 1.00 \\
\hline Intermediate & 566 & & & 2.00 & 2.00 \\
\hline Advanced & 1,007 & & & 3.00 & 3.00 \\
\hline Income & 1,542 & 0.51 & 0.29 & 0.00 & 1.00 \\
\hline Marital status & 1,611 & 0.67 & 0.47 & 0.00 & 1.00 \\
\hline
\end{tabular}

TABLE 5 | Pairwise correlations.

(1)

$\begin{array}{lc}\text { (1) CFC_Future } & 1.00 \\ \text { (2) CFC_Immediate } & -0.43^{\star \star \star} \\ \text { (3) Political trust } & 0.18^{\star \star \star} \\ \text { (4) Institutionalized participation (IP) } & 0.13^{\star \star \star} \\ \text { (5) Non-institutionalized participation (NIP) } & 0.20^{\star \star \star}\end{array}$

(2)

1.00
$-0.17^{\star \star \star}$
$-0.12^{\star \star \star}$
$-0.27^{\star \star \star}$

(3)

1.00
$0.10^{\star \star \star}$
$0.09^{\star \star}$

(4)

(5)

Entries are pairwise correlations with Bonferroni-adjusted significance level. ${ }^{* *} \mathrm{p}<0.001 ;{ }^{* *} \mathrm{p}<0.01$

There is a negative correlation between CFC-Future and CFCimmediate $(\mathrm{r}=-0.43, p<0.001)$, which is in line with what is reported by CFC-future has positive correlations with both IP $(\mathrm{r}=$ $0.13, p<0.001)$ and NIP $(\mathrm{r}=0.20, p<0.001)$, while the corresponding results are negative for CFC-immediate (IP: $\mathrm{r}=$ $-0.12, p<0.001$; NIP: $r=-0.27, p<0.001)$. Hence, people who focus on the more distant future are more likely to be active in both forms of participation, whereas those who focus more on the immediate future are less likely to be involved in any political activity. CFC-Future also has a positive correlation with political trust ( $\mathrm{r}=0.18, p<0.001$ ), which shows that people who focus more on the distant future have higher political trust, whereas the negative correlation for CFC-Immediate $(r=-0.17, p<0.001)$ shows that those who focus on the immediate future have lower trust on average.

Table 6 shows the results of OLS regression analyses for both kinds of political participation. Model one includes CFC-Future, CFCImmediate, and political trust, whereas Model two also includes the control variables. In Model 3, we also include interaction terms between the two CFC subscales and political trust.

For CFC-Future, the significant positive relationships persist after controlling for other factors for both IP $(\beta=2.31, p<0.001)$ 
TABLE 6 | Multiple regression models (OLS).

\begin{tabular}{|c|c|c|c|c|c|c|}
\hline & \multicolumn{3}{|c|}{ Institutionalized participation (IP) } & \multicolumn{3}{|c|}{ Non-institutionalized participation (NIP) } \\
\hline & (1) & (2) & (3) & (1) & (2) & (3) \\
\hline \multicolumn{7}{|l|}{ Independent variables } \\
\hline CFC-Future & & $\begin{array}{l}2.31^{\star \star} \\
(0.79)\end{array}$ & $\begin{array}{c}0.73 \\
(1.89)\end{array}$ & $\begin{array}{l}1.93^{\star \star} \\
(0.60)\end{array}$ & $\begin{array}{l}1.51^{*} \\
(0.62)\end{array}$ & $\begin{array}{l}4.37^{\star \star} \\
(1.52)\end{array}$ \\
\hline CFC-Immediate & & $\begin{array}{l}-1.5 \\
(0.77)\end{array}$ & $\begin{array}{l}-1.35 \\
(1.90)\end{array}$ & $\begin{array}{c}-4.45^{\star \star \star} \\
(0.60)\end{array}$ & $\begin{array}{c}-4.52^{\star \star \star} \\
(0.62)\end{array}$ & $\begin{array}{c}-3.64^{*} \\
(1.52)\end{array}$ \\
\hline \multicolumn{7}{|l|}{ Moderator } \\
\hline Political trust & $\begin{array}{l}1.87^{\star} \\
(0.76)\end{array}$ & $\begin{array}{l}0.67^{\star} \\
(0.32)\end{array}$ & $\begin{array}{l}0.64^{\star} \\
(0.32)\end{array}$ & $\begin{array}{c}0.28 \\
(0.25)\end{array}$ & $\begin{array}{c}0.29 \\
(0.26)\end{array}$ & $\begin{array}{c}0.32 \\
(0.26)\end{array}$ \\
\hline \multicolumn{7}{|l|}{ Control variables } \\
\hline Age & $\begin{array}{c}-1.67^{\star} \\
(0.73)\end{array}$ & $\begin{array}{c}0.18^{\star \star \star} \\
(0.04)\end{array}$ & $\begin{array}{c}0.18^{\star * \star} \\
(0.04)\end{array}$ & & $\begin{array}{c}-0.12^{\star \star \star} \\
(0.03)\end{array}$ & $\begin{array}{c}-0.12^{\star \star \star} \\
(0.03)\end{array}$ \\
\hline Gender & $\begin{array}{l}0.78^{\star} \\
(0.31)\end{array}$ & $\begin{array}{l}-1.21 \\
(1.34)\end{array}$ & $\begin{array}{l}-1.14 \\
(1.35)\end{array}$ & & $\begin{array}{c}-5.12^{\star \star \star} \\
(1.07)\end{array}$ & $\begin{array}{c}-5.16^{\star \star \star} \\
(1.07)\end{array}$ \\
\hline \multicolumn{7}{|l|}{ Education (ref. Basic) } \\
\hline Intermediate & & $\begin{array}{c}0.28 \\
(3.98)\end{array}$ & $\begin{array}{c}0.47 \\
(3.98)\end{array}$ & & $\begin{array}{c}0.01 \\
(3.23)\end{array}$ & $\begin{array}{l}-0.01 \\
(3.22)\end{array}$ \\
\hline Advanced & & $\begin{array}{c}1.88 \\
(3.97)\end{array}$ & $\begin{array}{l}2.08 \\
(3.98)\end{array}$ & & $\begin{array}{c}2.48 \\
(3.22)\end{array}$ & $\begin{array}{c}2.47 \\
(3.22)\end{array}$ \\
\hline Household income & & $\begin{array}{l}-3.62 \\
(2.76)\end{array}$ & $\begin{array}{l}-3.77 \\
(2.76)\end{array}$ & & $\begin{array}{c}-8.83^{\star \star \star *} \\
(2.21)\end{array}$ & $\begin{array}{c}-8.66^{\star \star \star} \\
(2.21)\end{array}$ \\
\hline Marital status & & $\begin{array}{l}-0.76 \\
(1.66)\end{array}$ & $\begin{array}{l}-0.71 \\
(1.66)\end{array}$ & & $\begin{array}{c}0.46 \\
(1.32)\end{array}$ & $\begin{array}{c}0.42 \\
(1.32)\end{array}$ \\
\hline \multicolumn{7}{|l|}{ Interactions } \\
\hline CFC-Future X Political trust & & & $\begin{array}{c}0.32 \\
(0.34)\end{array}$ & & & $\begin{array}{c}-0.56^{\star} \\
(0.27)\end{array}$ \\
\hline CFC-Immediate X Political trust & & & $\begin{array}{l}-0.04 \\
(0.35)\end{array}$ & & & $\begin{array}{c}-0.16 \\
(0.28)\end{array}$ \\
\hline Constant & $\begin{array}{c}55.86^{\star \star \star} \\
(1.72)\end{array}$ & 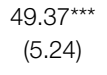 & $\begin{array}{c}49.21^{\star \star \star} \\
(5.24)\end{array}$ & $\begin{array}{c}72.77^{\star \star \star} \\
(1.4)\end{array}$ & $\begin{array}{c}89.37^{\star \star \star} \\
(4.17)\end{array}$ & 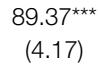 \\
\hline Observations & 1,179 & 1,104 & 1,104 & 1,298 & 1,213 & 1,213 \\
\hline R-squared & 0.03 & 0.04 & 0.05 & 0.08 & 0.13 & 0.14 \\
\hline
\end{tabular}

Entries are coefficients from a linear regression analysis (OLS) with standard errors in parentheses. ${ }^{* * *} \mathrm{p}<0.001,{ }^{* *} \mathrm{p}<0.01,{ }^{*} \mathrm{p}<0.05$.

and NIP $(\beta=1.51, p<0.001)$. For CFC-Immediate, the negative link grows just insignificant for IP $(\beta=-1.50, p=0.051)$ after controlling for other factors, while it persists for NIP $(\beta=-4.52$, $p<0.001)$. Figure 2 visualizes the implications of the results of Models 2.

For CFC-Future, the predicted participation in IP moves from about 53 for people with the lowest CFC-Future scores to 67 on the $0-100$ scale for those with the highest concern for the future. For NIP, the corresponding changes are from 70 on the $0-100$ scale to about 79 .

The negative coefficient for CFC-Immediate and IP entails that predicted participation drops from about 64 to about 55 as CFC-Immediate scores increases. For NIP, the predicted score drops from 88 for people who are unlikely to focus exclusively on the immediate future to about 61 for people who focus mainly on the immediate future.

Hence, $\mathrm{H} 1 \mathrm{a}$ is supported since we find the expected positive relationship between CFC-Future and IP, while $\mathrm{H} 1 \mathrm{~b}$ is rejected since the association between CFC-Immediate and IP is negative, but it is non-significant at a $p<0.05$ threshold, and the implications also appear modest. $\mathrm{H} 2 \mathrm{a}$ is rejected since we find a positive association between CFC-Future and IP rather than the expected negative association, and $\mathrm{H} 2 \mathrm{~b}$ is also rejected since the association is negative rather than the expected positive association.

To examine the moderating role of political trust in these relationships, we first notice that the results in Models two show that people with high trust are more likely to engage in IP ( $\beta=0.67, p=0.035)$, whereas the relationship with NIP is nonsignificant $(\beta=0.29, p=0.258)$. However, political trust may play an important role by moderating the relationships between the CFC-scales and participation, which is examined in Models 3. The results show that there is a significant interaction term for political trust and CFCFuture when it comes to NIP $(\beta=-0.56, p=0.039)$, whereas all other interaction terms are non-significant. Figure 3 visualizes the implications of this result.

The results show that the positive association only exists for people with low levels of political trust that there is a positive association, whereas the association is negligible, and even grows negative (albeit insignificant), for people with high levels of trust. Hence, future-oriented people who distrust the political system and actors engage in elite-challenging activities to get their political views across. Worries over future problems, including climate change and sustainability, are communicated to decisionmakers through less institutionalized activities and it is therefore 

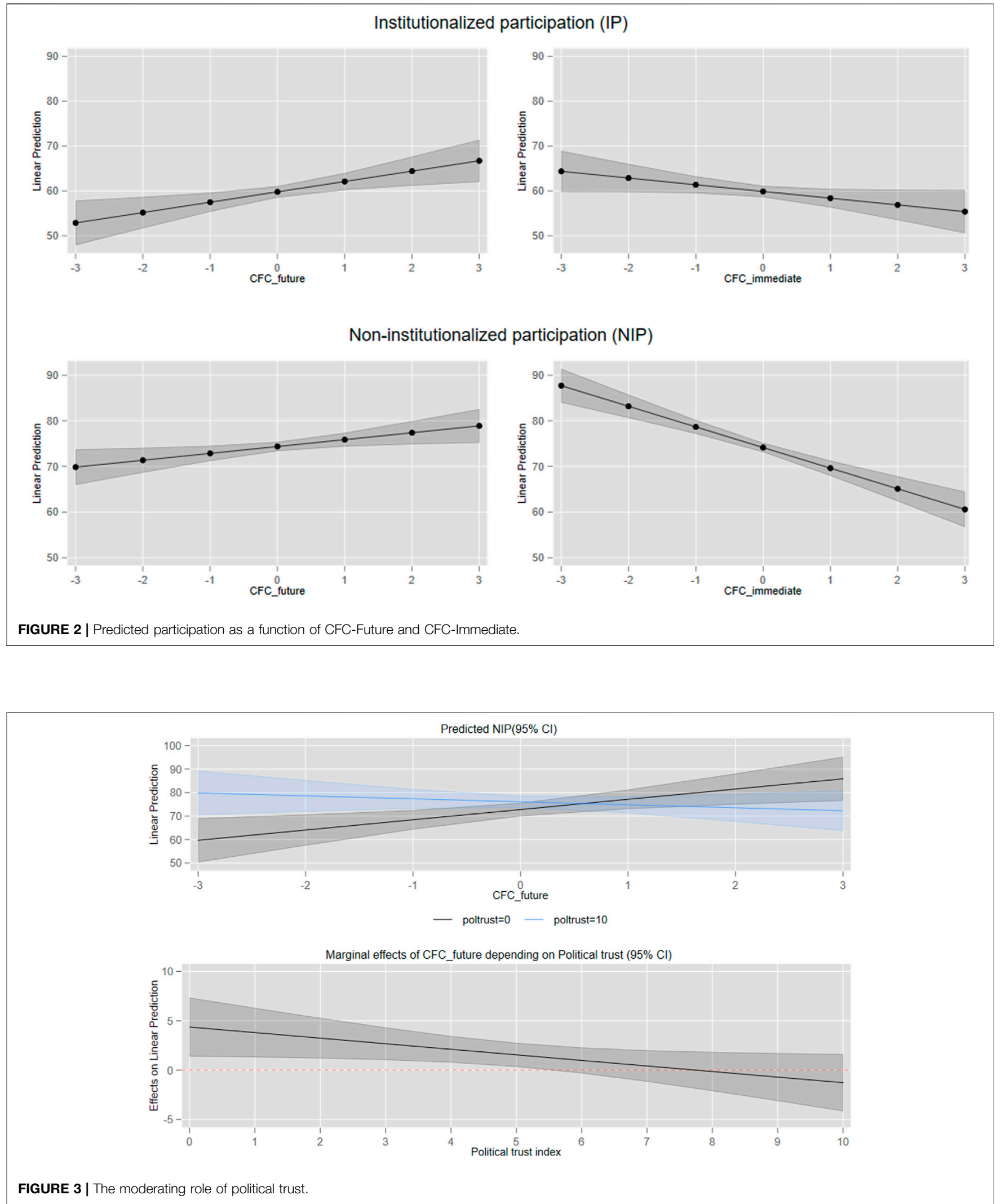
important that decision-makers remain attentive to these channels.

\section{DISCUSSION}

These findings have important implications for the link between considerations of future consequences and political participation.

First, we replicated the two-dimensional structure of future consequences found by Joireman et al. (2012). This then lends further credit to the notion that it is important to distinguish between considerations of future consequences (CFC-Future) and more immediate consequences (CFCImmediate) to appreciate how this phenomenon is linked to other psychological and social phenomena.

We here focus on the links to political participation between elections, and our empirical results show that these two dimensions have disparate associations with institutionalized and non-institutionalized forms of political participation.

Our results show that citizens with high scores on the CFCFuture index - who are more aware of consequences in the distant future - are more likely to engage in institutionalized political activities between elections.

This is in line with previous research suggesting similar links between the associated concept of delay discounting and participation in elections, although our findings are novel both in using the CFC-scale and in examining political participation between elections, which is arguably more important than voting for bringing specific issues to the attention of formal political decision-makers. While we initially find the expected negative link between CFCImmediate and institutionalized participation, this grows insignificant when including other factors, which suggests that the differences may well be due to other factors than how people consider immediate consequences. We are therefore unable to replicate the findings of Hill (2020), who find that people with present-bias are less likely to vote. However, this may also be because we consider more demanding activities between elections that last over a longer time period.

It is worth noting that a similar pattern for CFC-Future and non-institutionalized participation (NIP) exists, while we also find a strong negative link between CFC-Immediate and NIP. Our findings thereby show few pronounced differences between IP and NIP when it comes to thinking about future consequences. Those who engage in political activities between elections, regardless of the type of participation, tend to think about the world in terms of longer time horizons than those who remain passive. This result thereby contradicts a popular view of politically engaged ordinary citizens being myopic and too present-biased and thereby lends credit to the studies challenging this assertion (Christensen and Rapeli, 2021).

Our results do thereby not support assertions that NIP is predominantly "spontaneous" actions by individuals unwilling to commit to long-term efforts (Stolle and Hooghe, 2011: 139). If anything, those who care more about immediate consequences are less likely to engage in NIP.

Our study also has important findings regarding the role of political trust, since we find that political trust moderates the relationship between CFC-Future and NIP. This entails that the relationship between CFC-Future and NIP only exists for people with low political trust, whereas it is negligible for those with high political trust. This shows a conundrum for ensuring democratic responsiveness for the concerns voiced by people concerned about the future, but with low trust in the existing political system. As Huttunen (2021) shows, involvement in elite challenging activities does not necessarily entail that these activists reject the traditional representative system or that they want more participatory democracy. Nevertheless, as they exceedingly rely on activities not aimed at formal political decision-makers, there is a risk that their concerns are neglected, further exacerbating their dismay with the functioning of the political system. There is therefore a need to ensure that political decision-making remains responsive to demands raised via alternative channels of political participation.

These results come with some potential caveats. First, the results are limited to one country with its particular political characteristics. Further research will therefore be necessary to explore whether and how results might be generalized. Previous research has also suggested that particular environments are more or less conducive to citizens' future orientations (Pérez and Tavits, 2017). However, more comparative efforts are needed to establish whether similar associations can be established in different institutional, economic, and cultural settings.

Finally, it must be noted that the survey was fielded during the COVID-19 pandemic. While this should probably not affect the general findings (cf. Peyton et al., 2021), it is possible that the pandemic circumstances influenced the levels of CFC in our respondents, or that it changed who had engaged or not engaged in recent political activities compared to under "normal" political circumstances. A repetition of the study in another time context would therefore be relevant.

These comments notwithstanding, the biggest and simplest finding of our study is that individual time perspective has important implications for whether and how people participate in politics. The CFC-framework provides us with a useful mechanism for examining this, and the empirical data support this broad conclusion: How people think about the future is reflected in their propensity to take part in certain political activities. The time horizons of citizens thus translate into the political arena through democratic participation. Previous research with the CFC-framework elicits that future orientation also affects policy preferences. We believe there could be many more aspects of political relevance worth investigating for future studies.

\section{DATA AVAILABILITY STATEMENT}

The raw data supporting the conclusion of this article will be made available by the authors, without undue reservation. 


\section{AUTHOR CONTRIBUTIONS}

MK designed the study, identified the relevant theoretical frameworks for analyzing future orientation, and drafted the article. HC designed the study, identified the relevant theoretical frameworks for analyzing political participation, organized the data collection, analyzed the data, and modified the article.

\section{REFERENCES}

Abrams, D., and Travaglino, G. A. (2018). Immigration, Political Trust, and Brexit - Testing an Aversion Amplification Hypothesis. Br. J. Soc. Psychol. 57 (2), 310-326. doi:10.1111/bjso.12233

Ahvenharju, S., Lalot, F., Minkkinen, M., and Quiamzade, A. (2021). Individual Futures Consciousness: Psychology behind the Five-Dimensional Futures Consciousness Scale. Futures 128, 102708. doi:10.1016/j.futures.2021.102708

Ahvenharju, S., Minkkinen, M., and Lalot, F. (2018). The Five Dimensions of Futures Consciousness. Futures 104, 1-13. doi:10.1016/j.futures.2018.06.010

Bäck, M., and Christensen, H. S. (2016). When Trust Matters-A Multilevel Analysis of the Effect of Generalized Trust on Political Participation in 25 European Democracies. J. Civil Soc. 12 (2), 178-197. doi:10.1080/17448689.2016.1176730

Basta, K. (2020). "Time’s up!": Framing Collective Impatience for Radical Political Change. Polit. Psychol. 41 (4), 755-770. doi:10.1111/pops.12649

Bickel, W. K., and Marsch, L. A. (2001). Toward a Behavioral Economic Understanding of Drug Dependence: Delay Discounting Processes. Addiction 96 (1), 73-86. doi:10.1046/j.1360-0443.2001.961736.x

Biondolillo, M., and Epstein, L. (2021). Constructing a Performance Measure of Future Time Orientation. J. Personal. Assess. 103 (2), 278-288. doi:10.1080/ 00223891.2019 .1705843

Blumer, Y. B., Braunreiter, L., Kachi, A., Lordan-Perret, R., and Oeri, F. (2018). A Two-Level Analysis of Public Support: Exploring the Role of Beliefs in Opinions about the Swiss Energy Strategy. Energ. Res. Soc. Sci. 43, 109-118. doi:10.1016/ j.erss.2018.05.024

Borg, S., Kestilä-Kekkonen, E., and Wass, H. (2020). Politiikan Ilmastonmuutos Eduskuntavaalitutkimus 2019. Publications of the Ministry of Justice, Reports and Guidelines, 5.

Brady, H. E. (1999). "Political Participation," in Measures of Political Attitudes. Editors J. P. Robinson, P. R. Shaver, and L. S. Wrightsman (San Diego, CA: Academic Press).

Christensen, H. S., and Rapeli, L. (2021). Immediate Rewards or Delayed Gratification? A Conjoint Survey experiment of the Public's Policy Preferences. Policy Sci 54, 63-94. doi:10.1007/s11077-020-09408-w

Dalton, R. J. (2008). Citizenship Norms and the Expansion of Political Participation. Polit. Stud. 56 (1), 76-98. doi:10.1111/j.14679248.2007.00718.x

Dietz, T., Dan, A., and Shwom, R. (2007). Support for Climate Change Policy: Social Psychological and Social Structural Influences*. Rural Soc. 72 (2), 185-214. doi:10.1526/003601107781170026

Downs, A. (1957). An Economic Theory of Political Action in a Democracy. J. Polit. Economy 65 (2), 135-150. doi:10.1086/257897

Falk, A., Kosse, F., and Pinger, P. (2020). Re-Revisiting the Marshmallow Test: A Direct Comparison of Studies by Shoda, Mischel, and Peake (1990) and Watts, Duncan, and Quan (2018). Psychol. Sci. 31 (1), 100-104. doi:10.1177/ 0956797619861720

Fowler, J. H., and Kam, C. D. (2006). Patience as a Political Virtue: Delayed Gratification and Turnout. Polit. Behav. 28, 113-128. doi:10.1007/s11109-0069004-7

Gamson, W. A. (1968). Power and Discontent. USA: Dorsey Press.

Gelman, A. (2007). Struggles with Survey Weighting and Regression Modeling. Statist. Sci. 22 (2), 153-164. doi:10.1214/088342306000000691

Grzymala-Busse, A. (2011). Time Will Tell? Temporality and the Analysis of Causal Mechanisms and Processes. Comp. Polit. Stud. 44 (9), 1267-1297. doi:10.1177/0010414010390653

Hill, S. J. (2020). Following through on an Intention to Vote: Present Bias and Turnout. Psrm 8 (4), 803-810. doi:10.1017/psrm.2018.56

\section{FUNDING}

This study was made possible with the support of the Strategic Research Council at the Academy of Finland (Grant no's. 335980, 335989). Åbo Akademi University's APC-Pool supported the open access publication of this article.

Hooghe, M., and Marien, S. (2013). A Comparative Analysis of the Relation Between Political Trust and Forms of Political Participation in Europe. Eur. Soc. 15, 131-152. doi:10.1080/14616696.2012.692807

Huttunen, J. (2021). Young Rebels Who Do Not Want a Revolution: The Nonparticipatory Preferences of Fridays for Future Activists in Finland. Front. Polit. Sci. 3. doi:10.3389/fpos.2021.672362

Jacobs, A. M., and Matthews, J. S. (2012). Why Do Citizens Discount the Future? Public Opinion and the Timing of Policy Consequences. Br. J. Polit. Sci. 42 (4), 903-935. doi:10.1017/S0007123412000117

Joireman, J., and Liu, R. L. (2014). Future-oriented Women Will Pay to Reduce Global Warming: Mediation via Political Orientation, Environmental Values, and Belief in Global Warming. J. Environ. Psychol. 40, 391-400. doi:10.1016/ j.jenvp.2014.09.005

Joireman, J., Shaffer, M. J., Balliet, D., and Strathman, A. (2012). Promotion Orientation Explains Why Future-Oriented People Exercise and Eat Healthy. Pers Soc. Psychol. Bull. 38 (10), 1272-1287. doi:10.1177/0146167212449362

Kaase, M. (1999). Interpersonal Trust, Political Trust and Non-institutionalised Political Participation in Western Europe. West Eur. Polit. 22 (3), 1-21. doi:10.1080/01402389908425313

Kable, J. W. (2014). "Valuation, Intertemporal Choice, and Self-Control," in Neuroeconomics: Decision Making and the Brain. Editors P. W. Glimcher and E. Fehr. Second Edition (London: Academic Press), 173-192. doi:10.1016/B978-0-12-416008-8.00010-3

Kettunen, Anu. (2015). Conceptions of Time, the Individual and Society in Finnish Future Politics. Jyväskylä: University of Jyväskylä.

Khachatryan, H., Joireman, J., and Casavant, K. (2013). Relating Values and Consideration of Future and Immediate Consequences to Consumer Preference for Biofuels: A Three-Dimensional Social Dilemma Analysis. J. Environ. Psychol. 34, 97-108. doi:10.1016/j.jenvp.2013.01.001

Kooij, D. T. A. M., Kanfer, R., Betts, M., and Rudolph, C. W. (2018). Future Time Perspective: A Systematic Review and Meta-Analysis. J. Appl. Psychol. 103 (8), 867-893. doi:10.1037/apl0000306

Koskimaa, V., and Raunio, T. (2020). Encouraging a Longer Time Horizon: the Committee for the Future in the Finnish Eduskunta. J. Legislative Stud. 26 (2), 159-179. doi:10.1080/13572334.2020.1738670

Kurki, S. (2021). Towards National Systems Level Foresight? Understanding the Role and Future Directions of Citizen Participation in the Production of Finnish National Foresight Reports. Futures 132, 102781. doi:10.1016/ j.futures.2021.102781

Li, M. (2021). Uses and Abuses of Statistical Control Variables: Ruling Out or Creating Alternative Explanations? J. Business Res. 126, 472-488. doi:10.1016/ j.jbusres.2020.12.037

Lim, J. Y., and Moon, K.-K. (2020). Examining the Moderation Effect of Political Trust on the Linkage between Civic Morality and Support for Environmental Taxation. Ijerph 17 (12), 4476. doi:10.3390/ijerph17124476

Ma, Z., and Ma, R. (2021). Predicting Intentions to Vaccinate against COVID-19 and Seasonal Flu: The Role of Consideration of Future and Immediate Consequences. Health Commun., 1-10. doi:10.1080/10410236.2021.1877913

Marien, S., Hooghe, M., and Quintelier, E. (2010). Inequalities in Noninstitutionalised Forms of Political Participation: A Multi-Level Analysis of 25 Countries. Polit. Stud. 58 (10), 187-213. doi:10.1111/j.14679248.2009.00801.x

McClure, S. M., Laibson, D. I., Loewenstein, G., and Cohen, J. D. (2004). Separate Neural Systems Value Immediate and Delayed Monetary Rewards. Science 306 (5695), 503-507. doi:10.1126/science.1100907

Meirowitz, A., and Tucker, J. A. (2013). People Power or a One-Shot Deal? A Dynamic Model of Protest. Am. J. Polit. Sci. 57 (2), 478-490. doi:10.1111/ ajps. 12017 
Mischel, W., Shoda, Y., and Rodriguez, M. L. (1989). Delay of Gratification in Children. Science 244 (4907), 933-938. doi:10.1126/science.2658056

Mohammed, S., and Marhefka, J. T. (2020). How Have We, Do We, and Will We Measure Time Perspective? A Review of Methodological and Measurement Issues. J. Organ. Behav. 41 (3), 276-293. doi:10.1002/job.2414

Müller, S. (2021). The Temporal Focus of Campaign Communication. J. Polit online ahead of print. doi:10.1086/715165

Murphy, L., and Dockray, S. (2018). The Consideration of Future Consequences and Health Behaviour: a Meta-Analysis. Health Psychol. Rev. 12 (4), 357-381. doi:10.1080/17437199.2018.1489298

Murphy, L., and Murphy, G. (2018). Time to Drive: Present vs. Future Orientation and Self-Reported Driving Behaviour. Transportation Res. F: Traffic Psychol. Behav. 56, 1-13. doi:10.1016/j.trf.2018.03.026

Norris, P. (2002). Democratic Phoenix - Reinventing Political Activism. (Cambridge: Cambridge University Press).

Pateman, C. (1970). Participation and Democratic Theory. Cambridge: Cambridge University Press.

Pérez, E. O., and Tavits, M. (2017). Language Shapes People's Time Perspective and Support for Future-Oriented Policies. Am. J. Polit. Sci. 61 (3), 715-727. doi:10.1111/ajps.12290

Peyton, K., Huber, G. A., and Coppock, A. (2021). The Generalizability of Online Experiments Conducted during the COVID-19 Pandemic. J. Exp. Polit. Sci. 116. doi:10.1017.XPS.2021.1710.1017/xps.2021.17

Pierson, P. (2011). Politics in Time: History, Institutions, and Social Analysis. Princeton, NJ: Princeton University Press.

Rapeli, L., Bäck, M., Jäske, M., and Koskimaa, V. (2021). When Do You Want it? Determinants of Future-Oriented Political Thinking. Front. Polit. Sci. 3. doi:10.3389/fpos.2021.692913

Robinson, M. D., Cassidy, D. M., Boyd, R. L., and Fetterman, A. K. (2015). The Politics of Time: Conservatives Differentially Reference the Past and Liberals Differentially Reference the Future. J. Appl. Soc. Psychol. 45 (7), 391-399. doi:10.1111/jasp.12306

Schafer, J. (2021). Delayed Gratification in Political Participation. Am. Polit. Res. 49 (3), 304-312. doi:10.1177/1532673X20972352

Shavit, T., Lahav, E., and Shahrabani, S. (2014). What Affects the Decision to Take an Active Part in Social justice Protests? the Impacts of Confidence in Society, Time Preference and Interest in Politics. J. Behav. Exp. Econ. 52, 52-63. doi:10.1016/j.socec.2014.06.004

Sheffer, L., Loewen, P. J., Soroka, S., Walgrave, S., and Sheafer, T. (2018). Nonrepresentative Representatives: An Experimental Study of the Decision Making of Elected Politicians. Am. Polit. Sci. Rev. 112 (2), 302-321. doi:10.1017/ S0003055417000569

Stolle, D., and Hooghe, M. (2011). Shifting Inequalities. Eur. Societies 13 (1), 119-142. doi:10.1080/14616696.2010.523476
Strathman, A., Gleicher, F., Boninger, D. S., and Edwards, C. S. (1994). The Consideration of Future Consequences: Weighing Immediate and Distant Outcomes of Behavior. J. Personal. Soc. Psychol. 66 (4), 742-752. doi:10.1037/0022-3514.66.4.742

Tiirinki, H., Tynkkynen, L.-K., Sovala, M., AtkinsKoivusalo, S. M., Koivusalo, M., Rautiainen, P., et al. (2020). COVID-19 Pandemic in Finland - Preliminary Analysis on Health System Response and Economic Consequences. Health Pol. Technology 9, 649-662. doi:10.1016/j.hlpt.2020.08.005

Ting, T.-y. (2017). Struggling for Tomorrow: the Future Orientations of Youth Activism in a Democratic Crisis. Contemp. Soc. Sci. 12 (3-4), 242-257. doi:10.1080/21582041.2017.1385827

Vainio, A., Ovaska, U., and Varho, V. (2019). Not so Sustainable? Images of Bioeconomy by Future Environmental Professionals and Citizens. J. Clean Prod. 210, 1396-1405. doi:10.1016/j.jclepro.2018.10.290

Vainio, A., Varho, V., Tapio, P., Pulkka, A., and Paloniemi, R. (2019). Citizens' Images of a Sustainable Energy Transition. Energy 183, 606-616. doi:10.1016/ j.energy.2019.06.134

Van Deth, J. W. (2014). A Conceptual Map of Political Participation. Acta Polit. 49 (3), 349-367. doi:10.1057/ap.2014.6

Verba, S., Schlozman, K. L., and Brady, H. E. (1995). Voice and Equality: Civic Voluntarism in American Politics. (Cambridge, MA: Harvard University Press).

Wang, A. H.-E. (2018). Patience Moderates the Class Cleavage in Demand for Redistribution. Soc. Sci. Res. 70, 18-27. doi:10.1016/j.ssresearch.2017.10.005

Wang, A. H.-E. (2019). Patience, Dynamic of Protest, and Democratic Consolidation. Eur. Polit. Sci. 18, 473-490. doi:10.1057/s41304-018-0177-4

Conflict of Interest: The authors declare that the research was conducted in the absence of any commercial or financial relationships that could be construed as a potential conflict of interest.

Publisher's Note: All claims expressed in this article are solely those of the authors and do not necessarily represent those of their affiliated organizations, or those of the publisher, the editors and the reviewers. Any product that may be evaluated in this article, or claim that may be made by its manufacturer, is not guaranteed or endorsed by the publisher.

Copyright (c) 2021 Knudsen and Christensen. This is an open-access article distributed under the terms of the Creative Commons Attribution License (CC $B Y)$. The use, distribution or reproduction in other forums is permitted, provided the original author(s) and the copyright owner(s) are credited and that the original publication in this journal is cited, in accordance with accepted academic practice. No use, distribution or reproduction is permitted which does not comply with these terms. 